\title{
THE EFFECT OF MOISTURE CONTENT ON THE RETENTION AND DISTRIBUTION OF NANO-TITANIUM DIOXIDE IN THE WOOD
}

\author{
Younes Mohammadnia Afrouzi ${ }^{1}$, Pouya Marzbani ${ }^{2, \wedge}$, Asghar Omidvar ${ }^{1}$
}

\begin{abstract}
When chemically treating wood products is used to enhance the properties, the distribution of chemicals in the wood can be more important than the amount of chemical uptake. In this research, two moisture contents (MC) $(0$ and $25 \%)$ were used to study the effect of $\mathrm{MC}$ on the nanomaterial retention and distribution in cottonwood (Populus deltoides) sapwood treated with nano-titanium dioxide. The wood samples were impregnated by a full-cell process at three levels of nano- $\mathrm{TiO}_{2}$ concentration: 0,$5 ; 1$ and $1,5 \%$. The nanomaterial retention was calculated and SEM images were used to investigate the distribution of nanoparticles in the wood. The results showed that increasing the nano- $\mathrm{TiO}_{2}$ concentration caused more retention and the $\mathrm{MC}$ difference caused almost identical retention at 0,5 and $1 \%$ concentrations. Although the retention in the $0 \%$ MC samples was slightly more than those of $25 \% \mathrm{MC}$, this retention was significantly more in these samples $(0 \% \mathrm{MC})$ at $1,5 \%$ concentration. SEM images indicated that the nanoparticles had more uniform distribution in the $0 \% \mathrm{MC}$ samples than the $25 \% \mathrm{MC}$ ones and the difference was clearly visible at $1,5 \%$ concentration. Low MC ranges (about $0 \%$ ) are better than high MC's to impregnate cottonwood samples with nano- $\mathrm{TiO}_{2}$ by using the full-cell process.
\end{abstract}

Keywords: Full-cell process, impregnation, nanomaterial, Populus deltoides, SEM image.

\section{INTRODUCTION}

Permeability and chemical distribution are important properties in wood applications and depend on the manner of penetration and fluid flow into the wood (Yudodibroto and Walters 1977). These properties play a major role in the wood preservation and papermaking or pulp preparation processes (Siau 1984). One of the properties that has great impact on the wood treatability in addition to the absorption rate, is fluid distribution in the wood (also called micro-distribution) (Drysdale et al. 1980, Peters and Parameswaran 1980, Reimão and Palacios 1990). Because in some cases, treated wood that has a standard absorption rate and penetration depth, has become decayed over time (Omidvar and Schneider 2004). Some researchers believe that the decay is related to soft rot fungi attack (Dickinson and Sorkhoh 1976) and is a result of nonuniform distribution of preservative in the wood (Omidvar 1996, Omidvar and Schneider 2004). The factors such as tannin and nutrient presence can influence on the chemical distribution (Hulme and Butcher 1977). Therefore, conventional indices such as absorption rate are inadequate to obtain the required properties in wood impregnation. To insure proper treatment, the amount of absorbed chemical and its distribution in the wood should be investigated (Stefan et al. 2002).

Several factors affect the permeability and absorption of impregnation solution. Some of these factors are included: wood structure, moisture content (MC), impregnation method, features of impregnation solution, wood preparation method, etc. (Nicholas and Siau 1973). MC is one of the important factors that affects the chemical penetration into the wood. By studying the effect of MC on the permeability, Comstock and Cote (1968) concluded that the permeability of hardwoods decreases with increasing wood MC due to increasing the vessel volumes.

\footnotetext{
${ }^{1}$ Department of Wood Technology and Engineering, Faculty of Wood and Paper Engineering, Gorgan University of Agricultural Sciences and Natural Resources, Gorgan, Golestan province, Iran.

2 Department of Pulp and Paper Technology, Faculty of Wood and Paper Engineering, Gorgan University of Agricultural Sciences and Natural Resources, Gorgan, Golestan province, Iran.

^ Corresponding Author: marzbani.pouya@gmail.com

Received: 27.07.2013 Accepted: 07.08.2014
} 
One of the methods that can be considered as a suitable and high performance alternative for toxic preservatives is the nanomaterial utilization. Recently, the effects of nanomaterial utilization on improvement of the wood resistance against different wood destructive factors have been investigated in several studies (Kartal et al. 2009, Clausen et al. 2009, 2010, 2011, Afrouzi et al. 2013). Nano scale materials are defined as a set of substances where at least one dimension is less than approximately 100 nanometers (Kafarski 2007). Freeman and McIntyre (2008) reported that nano-metals with dimensions that are smaller than the wood pores $(100 \mu \mathrm{m}) \mathrm{and} /$ or intercellular pores $(400-600 \mathrm{~nm})$, can penetrate the porous structure of wood and thereby impact the wood resistance against destructive factors.

Nano-titanium dioxide (nano- $\mathrm{TiO}_{2}$ ) is used as a common catalyst for its optical and electrical properties, high photocatalytic activity, chemical stability, non-toxicity, good availability, and no corrosion due to light (Xu et al. 2008, Saha et al. 2011). It can create anti-bacterial coating due to UV absorption and its photocatalytic properties, and prevent the penetration of UV radiations (Daoud et al. 2005, Wong et al. 2006).

Knowing the relation between the wood $\mathrm{MC}$ and nano- $\mathrm{TiO}_{2}$ absorption rate is important and can influence the performance of impregnation process. Therefore, the aim of this study was to investigate the effect of MC on the nanomaterial retention and distribution in nano- $\mathrm{TiO}_{2}$ treated wood.

\section{MATERIAL AND METHODS}

\section{Sample Preparation}

Cottonwood (Populus deltoides) sapwood obtained from the research forest in Shastkalateh, Golestan province, Iran, was air dried and cut into 24 samples with dimensions of $50 \times 50 \times 3 \mathrm{~mm}$. They were divided into two groups that have two different moisture contents (MC) $(0 \%$ and $25 \% \mathrm{MC})$. To prepare the $0 \% \mathrm{MC}$ samples, 12 samples were placed in the oven at $103 \pm 2{ }^{\circ} \mathrm{C}$ for $24 \mathrm{~h}$ and kept in the laboratory desiccator containing silica gel as desiccant. Potassium nitrate salt was used to prepare the $25 \% \mathrm{MC}$ samples. A saturated solution of potassium nitrate salt was prepared and then, another 12 samples were placed into the incubator alongside the solution at $20^{\circ} \mathrm{C}$ for 21 days, which was stirred continuously by magnetic stirrer.

\section{Impregnation with $\mathrm{Nano}^{-\mathrm{TiO}_{2}}$}

Nano- $\mathrm{TiO}_{2}$ (Anatase phase, $20 \mathrm{~nm}$ particle size) suspensions were prepared at $0,5,1$ and $1,5 \%$ concentrations and then, the samples were impregnated by a full-cell process according to AWPA E10-08 (2008) standard method for testing wood preservatives, so that there were four replications for each treatment.

The preservative retention was calculated by following equation:

$$
\text { Retention }\left(\mathrm{kg} / \mathrm{m}^{3}\right)=(G C / V) \times 10
$$

which $G, C$ and $V$ are the absorbed preservative by the sample, the preservative amount in $100 \mathrm{ml}$ suspension and the sample volume, respectively.

In addition, studying the nanomaterial distribution in the wood was performed by SEM images taken from the treated samples. 


\section{RESULTS AND DISCUSSION}

\section{Nano- $\mathrm{TiO}_{2}$ retention}

The sample impregnation at three concentrations $(0,5 ; 1$ and $1,5 \%)$ caused different retentions, which increased with increasing the nanomaterial concentration. The results of Tukey statistical analysis test showed that there was no significant difference between the $0 \%$ and $25 \% \mathrm{MC}$ samples at 0,5 and $1 \%$ concentrations. Actually, the MC difference did not significantly influence the penetration of nano- $\mathrm{TiO}_{2}$ in the wood at the lower concentrations. However, nano- $\mathrm{TiO}_{2}$ retention was greater in the $0 \% \mathrm{MC}$ samples and increasing the concentration to $1,5 \%$ caused a clear retention difference (Table 1). Since the internal wood empty spaces, which are in the cell-wall, have been filled with water at the $25 \% \mathrm{MC}$, it limits the nanomaterial penetration into the wood but at the $0 \% \mathrm{MC}$ ( or near $0 \%$ ), more nanoparticles can penetrate the wood due to existence of more empty spaces. Actually, with increasing the wood MC, swelling occurs in the cell-wall and therefore, the volume of cell-wall pores or empty spaces decreases, which results in reducing the nanomaterial penetration into the wood (Nicholas and Siau 1973, Hosseinzadeh and Neyestani 1988).

Table 1. Nano- $\mathrm{TiO}_{2}$ retention in the 0 and $25 \%$ samples $\left(\mathrm{kg} / \mathrm{m}^{3}\right)$.

\begin{tabular}{cccc}
\hline \multirow{2}{*}{ MC (\%) } & \multicolumn{3}{c}{ Concentration (\%) } \\
\cline { 2 - 4 } & 0,5 & 1 & 1,5 \\
\hline & & & \\
\hline 0 & 3,59 & 7,06 & 9,45 \\
25 & 3,18 & 6,53 & 8,1 \\
\hline
\end{tabular}

\section{Nano- $\mathrm{TiO}_{2}$ distribution in the wood}

$\mathrm{SEM}$ images indicated that nano- $\mathrm{TiO}_{2}$ distribution was more suitable in the lower MC. As shown in figure 1 , the nanomaterial distribution became more uniform with decreasing the MC. It was not significantly clear at lower nanomaterial concentrations, but there was a significant difference in the nano- $\mathrm{TiO}_{2}$ distribution between the 0 and $25 \% \mathrm{MC}$ samples along with increasing the concentration. The most uniform distribution of nanomaterial occurred in the $0 \% \mathrm{MC}$ samples treated with $1,5 \%$ nano- $\mathrm{TiO}_{2}$. In the $25 \% \mathrm{MC}$ samples, the nanomaterial distribution was non-uniform and seemed uneven due to the moisture pressure as a barrier against proper impregnation (Nicholas and Siau 1973, Hosseinzadeh and Neyestani 1988). Since the internal wood spaces in the cell-wall were empty in the $0 \% \mathrm{MC}$ samples, there was no moisture pressure and therefore, the nanomaterial distribution was performed more uniformly. 

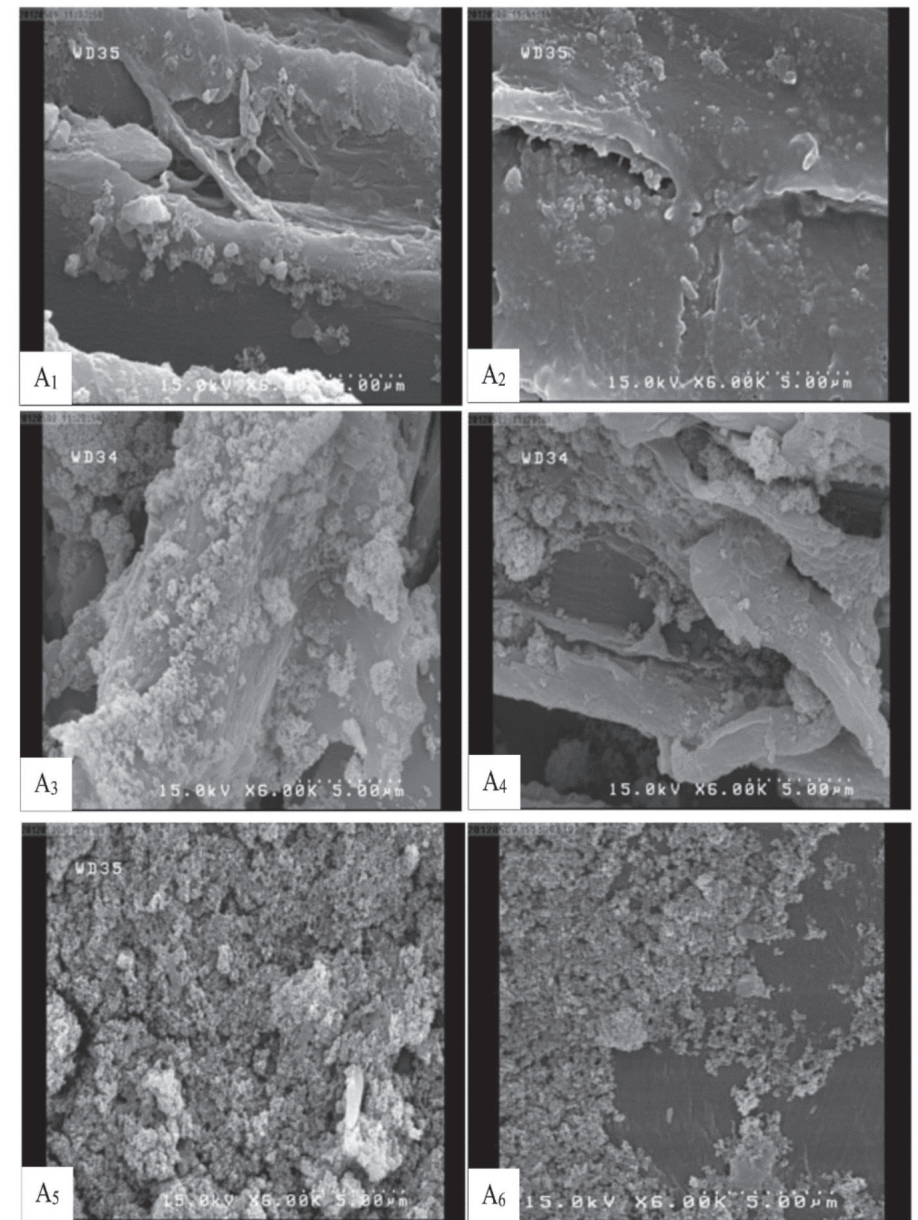

Figure 1. SEM images taken from the tangential section of nano- $\mathrm{TiO}_{2}$ treated samples: $\mathrm{a}_{1}$ : (the $0 \% \mathrm{MC}$ $10,5 \%$ concentration), $\mathrm{A}_{2}$ : (the $25 \% \mathrm{MC} / 0,5 \%$ concentration), $\mathrm{A}_{3}$ : (the $0 \% \mathrm{MC} / 1 \%$ concentration), $\mathrm{A}_{4}$ : (the $25 \% \mathrm{MC} / 1 \%$ concentration), $\mathrm{A}_{5}$ : (the $0 \% \mathrm{MC} / 1,5 \%$ concentration),

$\mathrm{A}_{6}$ : (the $25 \% \mathrm{MC} / 1,5 \%$ concentration).

\section{CONCLUSIONS}

The average of the retention and distribution uniformity of nano- $\mathrm{TiO}_{2}$ was greater in the $0 \% \mathrm{MC}$ samples and the difference between the 0 and $25 \% \mathrm{MC}$ samples increased with increasing the nanomaterial concentration. Due to non-existence of moisture pressure, greater uniformity of nanomaterial distribution occurred in the $0 \%$ MC samples that was significantly clear in the $1,5 \%$ concentration. Therefore, the $0 \% \mathrm{MC}$ samples treated with $1,5 \%$ nano- $\mathrm{TiO}_{2}$ showed the best performance and the $0 \% \mathrm{MC}$ (or near to it) is appropriate to achieve the most retention and uniform distribution. 


\section{REFERENCES}

Afrouzi, Y.M.; Omidvar, A; Marzbani, P. 2013. Effect of Artificial Weathering on the Wood Impregnated with Nano-Zinc Oxide. World Applied Sciences Journal 22 (9): 1200-1203.

American Wood Protection Association Standards, 2008. Standard method of testing wood preservatives by laboratory soil-block cultures. E10-08. In: Annual Book of AWPA Standards, Birmingham, AL. p. 364-372.

Clausen, C.A.; Green III, F.; Kartal, S.N. 2010. Weatherability and Leach Resistance of Wood Impregnated with Nano-Zinc Oxide. Nanoscale Research Letters 5(9): 1464-1467.

Clausen, C.A.; Kartal, S.N.; Arango, R.A.; Green III, F. 2011. The role of particle size of particulate nano-zinc oxide wood preservatives on termite mortality and leach resistance. Nanoscale Research Letters 6(1): $1-5$.

Clausen, C.A.; Yang, V.W.; Arango, R.A.; Green III, F. 2009. Feasibility of Nano-zinc oxide as a wood preservative. Proceedings of American Wood Protection Association 105: 255-260.

Comstock G.L.; Cote, W.A. 1968. Factors affecting permeability and pit aspiration in coniferous sapwood. Wood Science and Technology 2: 279-291.

Daoud, W.A.; Xin, J. H.; Zhang, Y.H. 2005. Surface Functionalization of Cellulose Fibers with Titanium Dioxide Nanoparticles and Their Combined Bactericidal Activities. Surface Science 599: 69-75.

Dickinson, D.J.; Sorkhoh, N.A.A.H. 1976. The micro-distribution of wood preservative. Scanning Electron Microscopy 9: 549-554.

Drysdale, J.A.; Dickinson, D.J.; Levy, J.F. 1980. Micro-distribution of a CCA preservative in five timbers of varying susceptibility to soft rot. Material und Organismen 15: 287-303.

Freeman, M.H.; C.R. McIntyre. 2008. Comprehensive review of copper-based wood preservatives. Forest Products Journal 58(11): 6-27.

Hosseinzadeh, A.; Neyestani, F. 1988. The effect of moisture content on the absorption rate and penetration depth of impregnation solution in the impregnated wooden sleepers. Forest and Pasture Research Institute, Tehran (In Persian).

Hulme, M.A.; Butcher, J.A. 1977. Soft-rot Control in Hardwoods Treated with Chromated Copper Arsenate Preservatives. I. Treatment Problems. Material und Organismen 12(2): 81-95.

Kafarski, P. 2007. Nanobiotechnology. Forum Akademickie Nr 7(8): 36-37.

Kartal, S.N.; Green III, F.; Clausen, C.A. 2009. Do the unique properties of nanometals affect leachability or efficacy against fungi and termites? International Biodeterioration and Biodegradation 63: 490-495.

Nicholas, D.D.; Siau, J.F. 1973. Factors Influencing the Treatability of Wood. In Wood Deterioration and its Prevention by Preservative Treatments, vol. II. Preservatives and Preservative Systems, Syracuse Univ. press.

Omidvar, A. 1996. The influence of moisture content on treaetability of red maple. Ph. D. Thesis, University of New Brunswick, Facculty of forestry and Environmental Management, Fredricton, N.B, Canada. 145p. 
Omidvar, A.; Schneider, M.H. 2004. Evaluation of fluid distribution in pressure treated wood in different flow directions. International Research Group on Wood Preservation. Document No.IRG/WP 04-40281.

Peters, G.A.; Parameswaran, N. 1980. Transmission Electron Microscopical Localization of Salt Preservative Components in Wood Cell Walls. Wood Science and Technology 14: 81-88.

Reimão, D.; Palacios, J.M. 1990. Microdistribution of water-borne preservatives in blue gum wood treated by full-cell process. International Research Group on Wood Preservation. Document No. IRG/WP/3617.

Saha, S.; Kocaefe, D.; Sarkar, D.K.; Boluk, Y.; Pichette, A. 2011. Effect of $\mathrm{TiO}_{2}$ - containing nanocoatings on the color protection of heat-treated jack pine. Journal of Coating Technology and Research 8(2): 183-190.

Siau, J.F. 1984. Transport processes in wood. Springer- Verlag, Berlin, Germany.

Stefan, J K.; Grzegorz, M.; Leslaw K. 2002. Non-linear Model for Wood Saturation. Kluwer Academic Publishers 46: 77-89.

Wong, Y.W.H.; Yuen, C.W.M.; Leung, M.Y.S.; Ku, S.K.A.; Lam, H.L.I. 2006. Selected Application of Nanotechnology in Textiles. Autex Research Journal 6(1): 1-8.

Xu, J.; Ao, Y.; Fu, D.; Yuan, C. 2008. Low-temperature preparation of anatase titania-coated magnetite. Journal of Physics and Chemistry of Solids 69(8): 1980-1984.

Yudodibroto, H.; Walters, C.S. 1977. A treatability classification for some tropical wood species. Proceedings of Annual Meeting of American Wood Preservers Association 73: 157-171. 